\title{
The Project Management K'nexercise: Using Role-Playing to Facilitate Learning About Design and Construction
}

\author{
Stephen J. Ressler \\ United States Military Academy
}

\section{INTRODUCTION}

This paper describes the use of a role-playing exercise to facilitate students' understanding of the interactions between the key players in the civil engineering design-construction process. It also describes the use of student journals as a means of assessing learning outcomes.

The role-playing exercise is used in CE400A, a 1.0 credit-hour seminar course taken by all seniors in the ABET-accredited civil engineering program at the United States Military Academy, West Point. CE400A was developed three years ago, in response to the program director's judgment that the civil engineering program lacked emphasis on professional practice issues. The course objectives, formulated to address this deficiency, are as follows:

- Explain the characteristics of a profession.

- Explain the roles and responsibilities of the members of the CE project team-Owner, Design Professional, Constructor, and Project Manager.

- Apply the ASCE Code of Ethics to the solution of an ethical problem in civil engineering.

- Demonstrate an understanding of the multi-faceted challenges facing civil engineers in professional practice.

- Develop a long-range plan for professional development.

To accomplish these objectives, the original CE400A program of instruction consisted of a series of seminars, case studies, and guest lectures by civil engineering practitioners, as well as a professional reading requirement. Students were required to keep journals documenting their observations, insights, criticisms, and questions about each of the lessons in the course. The journals served the dual purpose of assessing student learning and assigning a grade for the course.

I have served as the course director and principal instructor of CE400A since it was first offered in Academic Year 1995-96. At the conclusion of this first year, my analysis of student journals clearly indicated that the course had been a success, with one striking exception. Students' understanding of the roles and responsibilities of CE practitioners (the second objective listed above) was consistently poor. I had taught this subject on the first lesson of the course, in a traditional interactive lecture format, using the American Society of Civil Engineers' model (as depicted in Figure 1) to describe "the project team." Journal entries written immediately after this lesson indicated that the students could, in fact, explain the ASCE model; but in the following weeks, their comments about guest lectures clearly demonstrated that many could not

\footnotetext{
${ }^{1}$ Quality in the Constructed Product: A Guide for Owners, Designers and Constructors (ASCE Manual No. 73), American Society of Civil Engineers, 1990.
} 
apply the model to understand how a given civil engineering practitioner actually fit into the design-construction process. For example, in response to a guest lecture by a construction contractor, several students expressed admiration for his design work-a clear confusion of the roles of the design professional and constructor.

Evidently a single seminar did not (and probably could never) develop bona fide

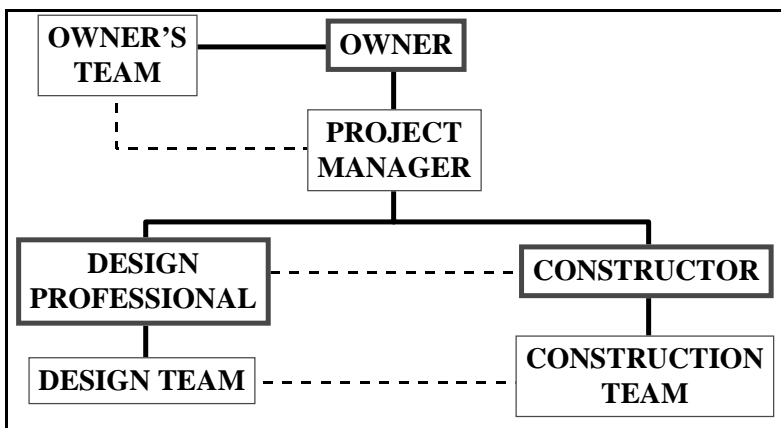

Figure 1. The ASCE Model of the Project Team understanding of the roles and responsibilities of CE practitioners. This should not have come as a surprise. As I reflected on the problem, it occurred to me that I had not truly understood the complex interactions between the key players in the design-construction process until I participated in that process myself-as a construction manager in a previous assignment with the Army Corps of Engineers. Thus I concluded that student learning of this topic might best be promoted via a design-construction project, in which students experience the process as participants.

I implemented such a project in CE400A the following year. The project requirement was to design and build a scale model of a building. Working in teams, students served in the specific roles of design engineer, construction contractor, project manager, and vendor. These teams had to perform their roles appropriately, in a competitive environment, in order to carry the project successfully from concept to design, from competitive bidding to construction contract, and from construction to project turnover. To provide a reasonably authentic, hands-on construction experience that was nonetheless achievable in a classroom setting, the project used $\mathrm{K}^{\prime}$ nex, ${ }^{\circledR} \mathrm{a}$ children's construction kit consisting of a variety of plastic structural components and connectors. The K'nex kits gave rise to the project's official title-The Project Management K’nexercise.

\section{A DESCRIPTION OF THE K'NEXERCISE}

The K'nexercise begins with the assignment of roles to student teams. During Academic Year 1996-97, with 64 students enrolled in the course, the teams were organized as follows:

- 4 teams (4 students each) were assigned as Architect-Engineer (A-E) Firms.

- 8 teams (4 students each) were assigned as Construction Contractors.

- 4 teams (2 students each) were assigned as Project Managers.

- 2 teams (4 students each) were assigned as construction material Vendors. 
The project proceeds in three phases, over a two-week period:

PHASE I (Design) - During this phase, the four A-E firms are asked to design a scale model of a simple building, using K'nex components for the structural system and paper for the facade. The A-E firms receive an architectural concept, a portion of which is shown in Figure 2. The door and window openings shown in the sketch serve as constraints on the structural design-beams, columns, and braces are not permitted to block these openings. The structural system must also be capable of carrying a specified loading_eight copies of the American Institute of Steel

Construction Manual of Steel Construction placed on the roof-without collapsing and without damaging the facade. Each team

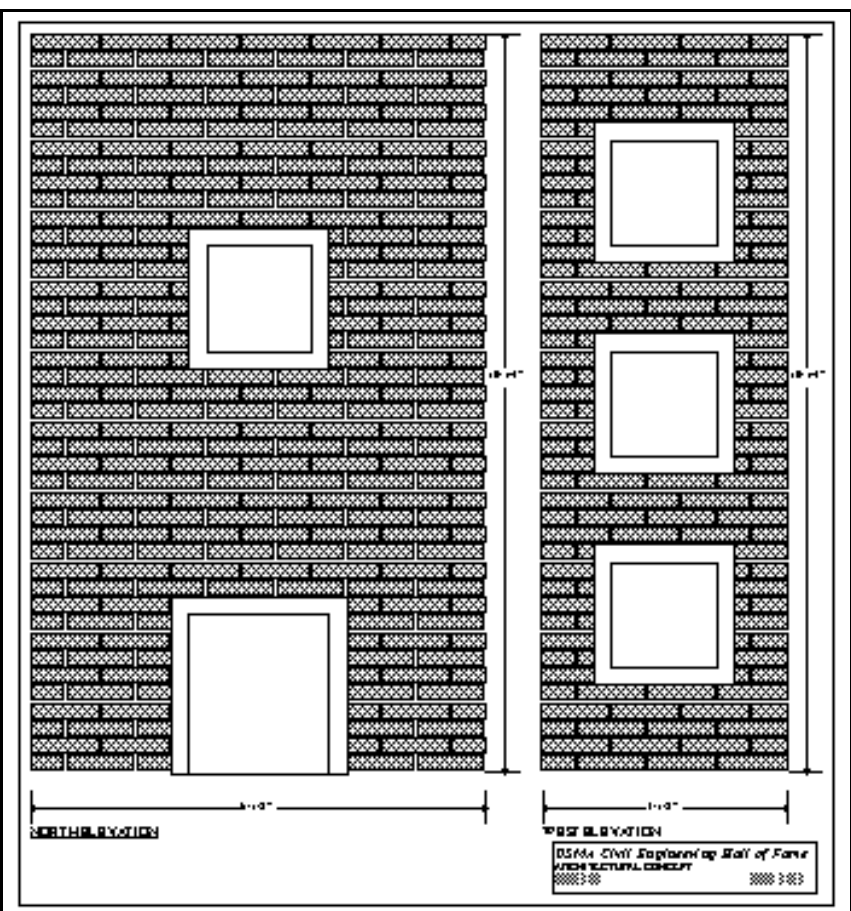

Figure 2. A portion of the architectural concept drawings. has one week to prepare plans, specifications, and a cost estimate for the structure. The project cost consists of three components: (1) material cost, based on a published list of retail prices for K' nex components, (2) labor cost, based on a specified labor rate (in dollars per second) multiplied by the estimated construction time (in seconds), and (3) a reasonable profit for the contractor (10\% of the project cost).

PHASE II (Design Review and Bid Preparation) - During this phase, each project manager receives a set of plans and specifications created by one of the A-E firms and performs a detailed design review. Each contractor also receives a set of plans and specifications, for the purpose of preparing a competitive bid for the project. (Two contractors are assigned to bid against each other on each of the four A-E firms' designs.) The bid is based on the contractor's own cost estimate, consisting of the material cost, labor cost, and profit. The vendors' role in the project is to purchase K'nex components from the manufacturer (the instructor) at wholesale prices, then sell them to the contractors at a profit. Contractors may buy from either of the two vendors; thus the vendors must attempt to set prices low enough to capture reasonable market share, but not so low that their profits are inadequate. Each vendor must publish a price list for their products, but contractors are permitted to bargain for reduced prices, for the purpose of lowering their bid prices or increasing profits. A contractor may request a written price commitment from one or both vendors, and vendors are permitted to offer reduced prices and special "package deals" in order to capture market share.

PHASE III (Contract Award, Construction, and Project Turnover) - This phase begins with each contractor submitting a sealed bid for construction of the building. Bids are opened, and construction contracts are awarded to the four low bidders. The contractors then "buy" their K'nex components from the vendors and start construction. Project managers record the construction time and calculate the actual construction cost (which becomes the basis for calculating the contractors' actual profits). The project managers also perform quality control 
inspections on the completed buildings and turn them over to the owner (a volunteer faculty member), who evaluates the building with respect to the original design criteria. The evaluation includes a load test (shown in Figure 3) and a check for inconsistencies between the structural and architectural designs (e.g., a diagonal brace running through a window opening).

The K'nexercise is a graded project, worth $25 \%$ of the course grade for CE400A. The grading scheme is designed to simulate the motivations and interests of the actual participants in the realworld design-construction process. Thus an A-E team gets a good grade if it produces a highquality, error-free design, whose estimated cost is within budget and whose actual construction cost did not exceed the estimate. A project management team gets a good grade if it does not overlook any design or construction errors. The contractor's grade is based on profit, with a substantial bonus for winning the contract and penalties for construction errors. The vendors'

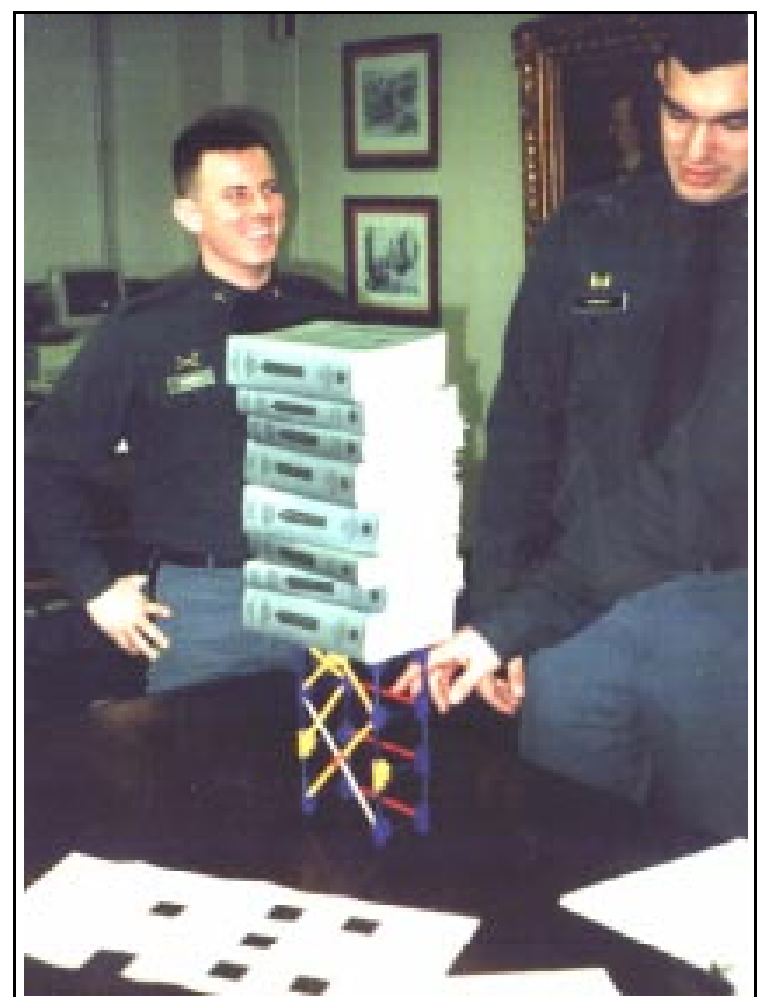

Figure 3. A load test, performed during the construction phase of the K'nexercise. grades are based entirely on their profits from the sale of K'nex components. This system creates a miniature free-market economy in the classroom and stimulates a very high level of interest among students.

\section{WHAT HAPPENED}

We ran the K'nexercise for the first time in February 1997. During Phase I, as intended, the A-E firms had little difficulty developing designs that satisfied the architectural and structural requirements. They soon discovered, however, that it was a far greater challenge to communicate their designs (in the form of plans and specifications), such that someone else would be able to build the structures correctly at a later date. The quality of the designs was generally good, but every one of the four teams had at least one error or inconsistency in their plans that created confusion for the project managers and contractors in the subsequent phases.

Phases II and III were chaotic, suggesting that my attempt to create a miniature free-market economy was successful. The two vendors engaged in a fierce competition for market share. One succeeded in convincing six of the eight contractors to buy all of their K'nex components from him; but to do so, he set his prices so low that he failed to make an acceptable profit. Similarly, several contractors committed economic suicide, submitting bids so low they were forced to perform the construction at a loss. In the rush to minimize construction time, one contractor built his structure backwards; the project manager discovered the error and duly reported it to the owner. During the construction phase, there were a number of heated arguments-between A-E firms and contractors, between contractors and vendors, between 
project managers and everyone else. Fortunately the K'nexercise rules did not allow for litigation.

\section{ASSESSMENT OF THE K'NEXERCISE}

Based on my observations and on those of the other instructors who assisted me, the implementation of the K'nexercise was quite successful. Our students clearly enjoyed themselves and seemed to appreciate the hands-on nature of the project. All 16 teams were reasonably successful in fulfilling their assigned roles. The students made plenty of errorsmistakes and ambiguities in plans, omissions in design reviews, misinterpretation of specifications by contractors, construction errors-but these were entirely consistent with the sorts of errors that often occur on real-world construction projects. Thus the exercise appeared to have been an authentic simulation of an actual project. If anything, the errors actually enhanced the educational value of the K'nexercise, as students saw firsthand how even a minor omission can compromise the success of an entire project.

Of course, successful implementation of the K'nexercise did not guarantee that the desired outcome was achieved. Had the project really promoted student learning about the roles and responsibilities of civil engineering practitioners? To answer this question, I turned again to the student journals. At the conclusion of the project, I asked the students to answer these questions in a journal entry during the following week:

- Based on this experience, what did you learn about the design-construction process and the interactions between the members of the project team?

- If you could "play the game" again, what would you do differently?

The students' responses were gratifying. Many demonstrated keen insights about the process, as illustrated by these brief excerpts:

"As engineers we always see the project on paper, and if the numbers work out then the design will work, but this is not how it really is. There is a whole human factor that plays an enormous role in the process which cannot be ignored. If anything, this is what I took away from the K'nexercise."

"A point worth noting is that various players in the process have the sole intention of making a dollar. This undermines the overall intent of satisfying the customer."

"Just like the real world, we developed time-saving strategies that eventually led to the saving of money."

"Our bid was about $\$ 160$ higher than our competitors. They cut their profit margin very low, and took about twice as long to build their project as they said they would, so they would have lost in the long run, but they won the contract. I think we could have cut some labor and material costs in order to win the contract."

"I was surprised at what a competitive business this is...."

The journal entries also demonstrated that the students could relate their own successes and failures to the roles and responsibilities of their real-world counterparts: 
"I am sure that with a real building, the writing and revision of specs takes quite a while, given the amount of detail necessary to ensure proper assembly of the building. Even with K'nex we saw how difficult it was to get a building made to the designer's original intentions using only words."

"The designers did not draw the picture out exactly how they wanted it; as a result, we built the building wrong."

"The Project Management Team seems to take on a lot of responsibility for the whole project without having hands-on in any of the steps."

Of course, not everyone got it exactly right. For example, one student wrote, "If we could play the game again...I believe that our team could be as underhanded and unscrupulous as the next

one, and we would come out on top." Fortunately, the journal is an effective means of two-way communication. Through written comments on this journal entry, I was able to correct the misperception and convince the student that the K'nexercise was not really intended to encourage unethical behavior.

On the whole, the journals demonstrated that the desired learning outcomes were achieved. Many students also used their journals to make suggestions about how the K'nexercise might be improved. And many of those recommendation have been incorporated into an improved version of the K'nexercise, which will be offered during the Spring semester of Academic Year 1997-98.

\section{REFERENCES}

American Society of Civil Engineers, Quality in the Constructed Product: A Guide for Owners, Designers and Constructors (ASCE Manual No. 73), ASCE, 1990

\section{STEPHEN J. RESSLER}

LTC Stephen J. Ressler is Professor and Deputy Head of the Department of Civil and Mechanical Engineering at the U. S. Military Academy, West Point. He graduated from USMA in 1979 and received a Ph.D. from Lehigh University in 1991. He is a registered P.E. in Virginia. He has taught courses in statics and dynamics, mechanics of materials, structural analysis, steel design, reinforced concrete design, and design of structural systems. 